\title{
A Incidência do Fantástico em A Morte e a Morte de Quincas Berro D’água e Dona Flor e Seus Dois Maridos
}

\author{
Marilene Carlos do Vale Melo
}

\section{SciELO Books / SciELO Livros / SciELO Libros}

MELO, MCV. A Incidência do Fantástico em A Morte e a Morte de Quincas Berro D’água e Dona Flor e Seus Dois Maridos. In: SWARNAKAR, S., FIGUEIREDO, ELL., and GERMANO, PG., orgs. Nova leitura crítica de Jorge Amado [online]. Campina Grande: EDUEPB, 2014, pp. 164-186. ISBN 978-85-7879-328-9. Available from SciELO Books $<$ http://books.scielo.org $>$.

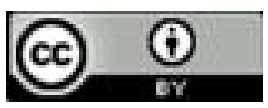

All the contents of this work, except where otherwise noted, is licensed under a Creative Commons Attribution $\underline{4.0 \text { International license. }}$

Todo o conteúdo deste trabalho, exceto quando houver ressalva, é publicado sob a licença $\underline{\text { Creative Commons }}$ Atribição 4.0. 


\title{
A Incidência do Fantástico em A Morte \\ e a Morte de Quincas Berro D'água e Dona Flor e Seus Dois IMaridos
}

\author{
Marilene Carlos do Vale Melo
}

\section{Resumo}

A narrativa fantástica constitui-se num gênero que, por lidar com o insólito, com uma realidade super-humana, com o sobrenatural ou com o inexplicável de qualquer tipo ou forma, remonta aos princípios da própria literatura. Assim, à luz de teorias sobre o Fantástico, defendidas por Todorov, Louis Vax dentre outros, nosso estudo se desenvolve destacando o clima do insólito ressaltado pelo discurso fantástico, circunstancialmente manifestado nas narrativas de Jorge Amado - a novela A morte e a morte de Quicas Berro d'Água o romance Dona Flor e seus dois maridos - . Nessas narrativas, o fantástico se opera ao nível das personagens que desafiam a morte e ultrapassam as leis da natureza. A ênfase do estudo recai sobre o jogo passado/presente, vida/morte (morte física e metafísica) das personagens Quincas Berro d’Água e Vadinho; o insubmisso Berro d’Água, cuja revolta vai além da rebeldia contra a sociedade e contra os limites da condição humana e as determinações do destino; e Vadinho, cuja morte em pleno carnaval, ajuda a definir seu caráter: como malandro, conhecia a ordem e a desordem e como espírito, volta à vida para realizar o desejo mais íntimo de Dona Flor.

Palavras-Chave: Fantástico. Insólito. Personagem. Morte. Vida. 164 


\section{Introdução}

A primeira ideia que se estabelece como conceito de Fantástico é que ele se define em relação aos conceitos de real e de imaginário; desenvolve-se partindo de um certo abandono da racionalidade. Porém, definir o que é Fantástico e que obras pertencem ao gênero, sempre foi uma tarefa difícil, considerando que o termo foi usado amplamente como sinônimo da literatura que se contrapõe ao realismo literário, ou mais especificamente que transgride as leis de causalidade. Louis Vax (1974, p.8) diz que "a narrativa fantástica gosta de nos apresentar, habitando o mundo real onde nos encontramos, homens como nós, postos de súbito em presença do inexplicável"; Cartex (Lê conte fantastique en france, p.8), afirma: "O Fantástico [...] se caracteriza [...] por uma introdução brutal do mistério no quadro da vida real". Todorov, fala que "na verdade o que distingue o fantástico narrativo é uma complexidade diante de um fato inacreditável, a hesitação entre uma explicação racional e realista e o acatamento do sobrenatural". Roger Caillois, em $A u$ Coeur du fantastique (p.161): "Todo o fantástico é ruptura da ordem estabelecida, irrupção do inadmissível no seio da inaceitável legalidade cotidiana".

Sendo assim, é possível observarmos a recorrência de termos como: Mistério, Mundo Irreal, Inexplicável, Vida Real, Inacreditável, Hesitação, Inusitado, Imaginário, Inadmissível, Absurdo, Sobrenatural, nos diversos conceitos, e que se manifestam nas narrativas fantásticas, constituídas como gênero, que, por lidarem com uma realidade super-humana, 
com o sobrenatural ou com o inexplicável de qualquer tipo ou forma, remontam aos princípios da própria literatura.

Quando, em uma narrativa, se dá um acontecimento inusitado que aparentemente não pode ser explicado pelas leis naturais, a hesitação experimentada pelas personagens ou pelos leitores, diante de um fato insólito, é que caracteriza o fantástico. O momento fantástico, segundo Louis Vax (1974, p.58), "aquele em que a imaginação se acha surdamente ocupada a minar o real [...]." Isto porque a narração fantástica caracteriza-se por manipular, sem entraves, o universo real, questionando a lógica racional dos acontecimentos absolutos e subvertendo a própria noção de realidade, de modo manifesto em seu discurso, passando a ser usado como recurso expressivo para evidenciar a ausência de fronteiras entre o real e o imaginário, o natural e o anormal. Logo, o fantástico se define como uma percepção particular de acontecimentos estranhos.

São alguns acontecimentos estranhos, inusitados, como a ruptura da realidade coesa e contínua, gerada pela desconstrução da realidade que conhecemos como verdadeira, que destacamos no estudo da incidência do fantástico em Jorge Amado.

Vale lembrar que o fantástico em Jorge Amado não é uma constante. $\mathrm{O}$ autor, circunstancialmente, usa esse recurso em algumas narrativas, como, por exemplo, $A$ morte e a morte de Quincas Berro d'Água e Dona Flor e seus dois marido, Nessas narrativas, o fantástico se opera ao nível das personagens que 
desafiam a morte e ultrapassam as leis da natureza. A ênfase do estudo recai sobre o jogo passado/presente, vida/ (morte física e metafísica) das personagens Quincas Berro d'Água e Vadinho. Nas duas narrativas, há o jogo de opostos manifestado na questão da dualidade da morte: a morte física $\mathrm{X}$ a morte metafísica. A primeira se contrasta com a morte metafísica e é entendida como ponto final da existência

Em A morte e a morte de Quicas Berro d'Água, Amado conta-nos, em tom lírico e divertido, a história de Joaquim Soares da Cunha, exemplar funcionário público, honesto pai de familia, massacrado pela mulher e pela sogra, que abandonou a vida respeitável familiar pela vida boêmia de Salvador, unindo-se a prostitutas e vagabundos, transformando-se no bêbado Quicas Berro d'Água. Instaura-se, assim, o conflito entre a ordem instituída pela sociedade dita burguesa e a liberdade da boemia.

Nessa narrativa, o clima do insólito já se manifesta no título, contrariando a expectativa convencional de uma narrativa do tipo biográfico - como Vida e morte de... - ao mesmo tempo, subverte a ideia do morrer como fato único, definitivo, não repetido. Observando rigorosamente o código do discurso fantástico, os acontecimentos são, desde as primeiras linhas, dados como problemáticos, a partir da referência à última frase de Quincas quando se joga no mar.. "Até hoje permanece certa confusão em torno da morte de Quincas Berro d’Água. Dúvidas para explicar detalhes absurdos, contradições no depoimento das testemunhas, lacunas diversas. Não há clareza sobre 
a hora, local e frase derradeira". (AMADO, 1976a, p.7).

O trecho acima remete à preocupação em buscar a verdade dos fatos, definindo o narrador como confiável e competente para narrar tais fatos. Porém, feitas as investigações necessárias, esse narrador confessa a irresolução do problema. Assim, duas versões permanecem: a da família, apoiada por vizinhos e conhecidos e a dos amigos de Quincas, da vida boêmia dos seus últimos anos de vida.

As versões remetem à dualidade: morte física $\mathrm{X}$ morte metafísica. A primeira: a tranquila morte matinal, numa pocilga miserável da Ladeira do Tubarão, sem testemunhas, sem aparato, sem palavras; a segunda, a morte metafísica, no mar, comentada e propalada na noite, presenciada por testemunhas idôneas que viram Quincas se jogar no mar, enquanto ouviam sua última frase, repetida, mais tarde, de boca em boca. "Segundo um trovador do mercado, passou-se assim":

No meio da confusão

Ouvia-se Quincas dizer:

“- Me enterro como entender

na hora que resolver. Podem

guardar seu caixão pra melhor ocasião.

Não vou deixar me prender em cova rasa no chão."

E foi impossível saber o resto de sua oração.

(AMADO, 1976, p.39, grifos do autor).

A linha do tempo desenvolve-se em três momentos importantes: a $1^{a}$ morte - moral (quando deixa a família para viver 
a vida boêmia): a $2^{\mathrm{a}}$ morte-física (no quarto da Ladeira do Tubarão) e a $3^{\mathrm{a}}$ morte - metafísica (no mar, como desejou). A ordem dos três momentos está marcada pela linha do tempo lógico, cronológico.

Assim, avisada da morte de Quincas, a família, preocupada em recuperar o nome e a imagem do homem digno que fora, tenta enterrá-lo segundo as normas burguesas. Entregue a uma funerária, o corpo de Quincas, livre dos trapos que usava na nova vida boêmia, transfigurou-se: "Penteado, barbeado, vestido de negro, camisa alva e gravata, sapatos lustrosos [..]. (p. 18)", voltou a ser Joaquim Soares da Cunha. Durante o velório, se evidencia o primeiro momento do Fantástico, que acontece somente para a filha de Quincas, enquanto velava o corpo do pai, no quarto imundo da ladeira do Tubarão:

Fisionomia melancólica, fitou o cadáver [...] Pousou os olhos no rosto barbeado. E levou um choque, o primeiro. Viu o sorriso. Sorriso cínico, imoral, de quem se divertia [...] um riso que ia se ampliando, alargando-se, que aos poucos ressoava na pocilga imunda. Ria com os lábios e com os olhos, olhos a fitarem o monte de roupa suja e remendada, esquecida num canto pelos homens da funerária. O sorriso de Quincas Berro d’Água. E Vanda ouviu as sílabas destacadas com nitidez insultante, no silêncio fúnebre: 
- Jararaca!

Assustou-se Vanda [...] Nem agora morto e esticado no caixão [...] ele se entregava. Ria além da boca e com os olhos, não era de admirar-se começasse a assobiar. E além do mais, um dos polegares [...] não estava devidamente cruzado sobre outro, elevando-se no ar, anárquico e debochativo.

- Jararaca! - disse de novo, e assobiou gaiatamente.

(AMADO, 1976a, p.18-19)

A surpresa e a hesitação tomam conta de Vanda, pensou: "Será que estou enlouquecendo? Sentiu faltar-lhe o ar... sua cabeça rodava." (p. 19).

A chegada de outra personagem, a irmã do morto, tia Marocas, não alterou a situação. Entrando no quarto, "Viu a sobrinha decomposta na cadeira, lívida, os olhos pregados na boca do morto." Quincas continuou com o sorriso cínico e debochado, além de falar insultos.

Ampliou-se o sorriso canalha de Quincas ao enxergar o vulto monumental da irmã. Vanda quis tapar os ouvidos, sabia, por experiência anterior, com que palavras ele amava definir Marocas, mas que adiantam mão sobre as orelhas para 
conter voz de morto? Ouviu:

- Saco de peidos! (p.19).

Até este momento, o fantástico se apresenta apenas para a filha, Vanda.

O segundo momento da narrativa criou o máximo efeito do fantástico e orientou para a segunda morte de Quincas. Tudo começou com a chegada dos amigos vagabundos e companheiros de farra de Quincas: Curió, Negro Pastinha, Cabo Martinho e Pé-de-Vento, que, de certa forma, constituem o elemento desarticulador da ordem moral e possibilitam a manifestação do fantástico.

Quando surgiram na porta do quarto, Pé-deVento adiantou a mão em cuja palma estava pousada a jia de olhos saltados. Ficaram parados na porta, uns por trás dos outros. Negro Pastinha avançava a cabeçorra para ver. Péde-Vento, envergonhado, guardou o animal no bolso. A família suspendeu a animada conversa, quatro pares de olhos hostis fitaram o grupo escabroso. Só faltava aquilo, pensou Vanda. Cabo Martim, que em matéria de educação só perdia para o próprio Quincas. Retirou da cabeça o surrado chapéu, cumprimentou os presentes. (p.26). 
Incomodados com a presença deles, todos da família combinaram voltar no dia seguinte para realizarem o enterro. Deixaram o "defunto" à responsabilidade dos quatro amigos de Quincas. Juntos, começaram a bebedeira, até decidirem ir à festa de mestre Manuel e buscar as mulheres. Agora, morto Quincas e com a cachaça enfraquecendo a força da censura, surgiu a disputa para saber quem seria o substituto de Quincas no coração de Quitéria do Olho Arregalado.

Ele adora ouvir uma cantiga. Cantavam os quatro... Quincas não perdia nem um só gole, nem um som, gostava de cantigas. Quando já estavam fartos de cantar, Curió perguntou:

- Não era hoje de noite a moqueca de mestre Manuel?

- Hoje mesmo...

Quincas estalou a língua. Já estavam atrasados, pois ainda tinham de ir buscar as mulheres, Curió expôs suas dúvidas:

- Tu quer ir?

- Tou por acaso aleijado para ficar aqui? Puseram Quincas em pé. Negro Pastinha comentou:

- Tá tão bêbado que não se aguenta... Vambora, Paizinho.

Quicas satisfeito da vida, num passo de 
dança, ia entre o Negro Pastinha e o Cabo Martim, de braços dados...

(AMADO, 1976a, p. 33)

O fantástico da situação utilizou-se desse momento para tirar os melhores efeitos. Enquanto Quincas levantou-se do caixão e acompanhou os amigos pelas ruas de Salvador, em última peregrinação, buscou realizar seu desejo, de escolher o seu próprio destino, o de morrer no mar. Assim, cumprindo o último ritual de brigas e bebedeiras, num misto de ficção e realidade, com lances fantásticos de mistério, sobrenatural e inesperado, o herói morreu pela segunda vez, no mar, como um velho marinheiro, livre das convenções sociais.

No meio do ruído, do mar em fúria, do saveiro em perigo, à luz dos raios, viram Quincas atirar-se às ondas e ouviram sua frase derradeira. Penetrava o saveiro nas águas calmas do quebra-mar, mas Quincas ficara na tempestade, envolto num lençol de ondas e espuma, por sua própria vontade. (p.38). 
Comparando os dois textos em estudo, constatamos que a morte física de Quincas e a de Vadinho aconteceram em circunstâncias semelhantes. Como Quincas Berro d'Água, Vadinho, o homem da noite, do jogo, da vadiagem, da rua e da alegria, amigo de jogadores, marginais e sem lugar na estrutura social, morreu na rua, em pleno domingo de carnaval. Esse é o ponto inicial da narrativa, um momento associado ao tempo carnavalesco, tempo de alegria obrigatória e planejada, com o inesperado da morte do maior folião baiano de todos os tempos: Vadinho.

A história de Dona Flor pode ser apresentada em quatro momentos distintos. O primeiro momento é o da viuvez de Flor, quando morreu seu marido, em pleno Carnaval, numa situação que ajudou a definir o caráter de Vadinho. Daí, a narrativa volta ao passado e o narrador nos apresenta a relação Vadinho/Flor.

Falando sobre a viuvez de Flor, Jorge Amado define a personalidade de Vadinho como malandro, caloteiro, jogador, mulherengo, amigo da noite, capaz de trazer à sua honrada e leal esposa os maiores sofrimentos. Há aqui muitos relacionamentos importantes. Por um lado, a visão exterior de Vadinho como malandro e rufião e irresponsável, é complementada por uma visão interna feita pelas recordações de Dona Flor e motivada pelo seu amor por esse homem tão seu oposto e, ao mesmo tempo, tão complementar a ela e ao seu estilo de vida.

Ocorreu, então, o jogo de contraste: a descrição do 
Vadinho feito pelas comadres e amigas de Flor (um Vadinho exterior), e a do Vadinho da memória de dona Flor, capaz de fazê-la ver todo um outro lado da vida e do relacionamento humano que a existência burguesa não deixava perceber. $\mathrm{Na}$ memória de Flor, Vadinho surgia como malandro e como ser do movimento e da própria vida. Como homem que fez com que ela pudesse se transformar plenamente em mulher capaz de transcender as convenções sociais da hierarquia, do poder, do dinheiro e, até mesmo, das propostas monogâmicas da religião e da sociedade, significando, para dona Flor, um modelo de liberdade.

Vale lembrar que durante todo o período de viuvez de Dona Flor, ficou evidente o esforço das amigas no sentido de fazer com que ela se relacionasse novamente com o mundo exterior, saindo do luto. Dona Flor resolveu abandonar seu estado de individualização dado pela viuvez e luto fechado e voltou ao reino dos amigos e do mundo. A perda de Vadinho, com sua morte, significou, para Flor, a falta do homem, o que logo foi superada com o segundo casamento, em condições opostas e bem mais satisfatórias. Este é o segundo momento da narrativa, quando Flor entrou em outra relação conjugal, casando com o farmacêutico, Teodoro.

O casamento com Teodoro transcorreu com tamanha tranquilidade que dona Flor escreve em carta a sua irmã Rosália: "O tempo passa e o doutor não muda. A mesma palidez, o mesmo sistema, o mesmo tato, sempre igual, um dia atrás do outro. Posso dizer o que vai acontecer a cada instante, 
no passar das horas, e sei cada palavra, porque hoje é igual a ontem" (AMADO, 1976b, p.255).

Comparado ao segundo marido, Teodoro, Vadinho é o sem-vergonha debochado, amoral, diferente de Teodoro. Disso Flor tinha consciência. Porém ela começou a pensar em Vadinho e a desejá-lo, como se sua vida estivesse incompleta, sem o outro lado que Vadinho representava e exprimia. Se estava satisfeita com o segundo casamento (é assim que o texto nos permite observar), por que aceitar "aquela" vida de antes, cheia de dúvidas, insatisfação e tormento, ao lado de Vadinho?

Assim, no quarto e último momento da narrativa, o fantástico se evidencia com a presença de Vadinho na alcova de Dona Flor.

No leito de ferro, nu [...] estava Vadinho deitado, a la godaça, e sorrindo lhe acenou com a mão. Sorriu-lhe em resposta, dona Flor. Quem pode resistir à graça do pedido, àquela face de moceneta e de cinismo...? Nem uma santa da igreja, quanto mais ela, dona Flor, simples criatura.

- Meu bem... - aquela voz querida, de preguiça lenta.

- Por que veio logo hoje? - perguntou Flor.

- Porque você me chamou. E hoje me 
chamou tanto que eu vim... - como se dissesse ter sido o seu apelo insistente e intenso, a ponto de fundir os limites do possível e do impossível Pois estou eu aqui, um bem, cheguei indagorinha...

(AMADO, 1976b, p. 293)

É o momento fantástico, o acontecimento inusitado, inacreditável, marcado pelo sobrenatural, onde se destaca a mistura do mundo material com o sobrenatural e apresentação de uma personagem, que, em vez de lutar para resolver contradições e dilemas íntimos, aceita os paradoxos e as incoerências que definem bem o humano. E, justamente porque se recusa a fazer escolhas e aceitar a vida como experiência múltipla, incoerente, se fortalece como ser humano.

O Fantástico aqui se opera ao nível das personagens: Flor e Vadinho. Diferente de Vanda que se surpreendeu com as reações de Quincas, morto, não há hesitação nem surpresa por parte de Flor. Assim, sem hesitação nem surpresa, a volta de Vadinho representa a realização de um grande desejo de Flor.

A insistência de "posse" de Flor se antepõe à resistência dela. É preciso lembrar que desde o início da narrativa, o autor deixa passar para o leitor o caráter íntegro e pudico, além do sentido de moralidade que caracteriza a personagem Flor. Isto cria um certo antagonismo entre o caráter de Flor e o de 
Vadinho. Flor nunca aceitou a amoralidade de Vadinho. Porem, o pudor e a moralidade de Flor não foram suficientemente fortes para reprimir seus desejos. Daí porque ela aceitou a volta de Vadinho, porque no fundo ela precisava de um homem como ele. Sendo pudica e moralista, como se explica a "aceitação" passiva da volta de Vadinho? Mas não era a vida tranquila ao lado de Teodoro que a satisfazia. Assim, se tinha a oportunidade de realizar e materializar (pelo menos essa era a sua ótica) seu grande desejo, Flor não deixou escapar. Isso fica evidente no jogo de sedução articulado por Vadinho, repetindo momentos da vida dos dois, como quando ele estava vivo:

Por duas ou três vezes naquele fim de tarde, Vadinho lhe repetira com vOz matreira, num sorriso de motejo: - Vamos ver quem pode mais, minha santa... Tu com teu doutor e teu orgulho e eu...

- Tu com o quê?

- Eu com meu amor... (p. 303).

Daí, Flor se dividiu entre a existência calma e pacífica com o segundo marido e a relação atribulada inconstante com Vadinho "morto" para as outras personagens, porém "muito vivo" na sua vida íntima. Por isso, se questiona, "aquele era um problema novo, nele não pensara Flor e nem soube contestar". Preocupada com a volta de Teodoro, manda Vadinho embora e diz: 
Lá vem ele, Vadinho, vai-te embora... Fiquei contente, muito contente, nem sabes, de te ver... Foi bom demais...

- Por que hei de ir, me diga?

- Ele chega e vai te ver aqui, que é que eu vou dizer?

- Tola, ele não me vê, só quem me vê és tu, minha flor de perdição.

(AMADO, 1976b, p 294)

Após saber que somente ela, Flor, pode "ver" Vadinho, teve a sensação de alívio. Mas essa sensação remeteu ao sentido de perda do marido, pela segunda vez, porque Vadinho voltou à vida boêmia de antes. Nesse sentido, percebemos um tom de dor e tristeza que se manifesta no texto mascarando esse sentimento, se confirma com a afirmativa de Flor: "Antes assim [...]", porque ela tinha consciência, naquele momento, que Vadinho não significava a mudança de seu comportamento, mas sim, a simples realização de seu desejo mais íntimo. É uma situação crítica porque fez com que ela se decidisse por tê-lo a seu lado não importando as implicações morais de seu desejo.

- Encornou... - disse Vadinho aplicando o termo justo. - Agora, nós, meu bem $[\ldots]$

- Aqui, não... - Pediu dona Flor, gastando os últimos resquícios de pudor 
e de respeito ao segundo esposo. Vamos pra sala...

Na sala, as portas do céu se abriram, irrompeu o canto de alegria. Onde já se viu vadiar de camisola? Dona Flor tão despida quanto ele, um da nudez do outro se vestindo e completando. Lança de fogo a traspassou, pela segunda vez Vadinho the comeu a honra, primeiro a de donzela, agora a de casada [...] Lá se foram pelos prados da noite até a fímbria da manhã. Nunca se dera assim, tão solta e tão fogosa, tão de gula acesa, tão em delírio. Ah! Vadinho, se sentias fome e sede, quer dizer de mim, mantida em regime magro e insosso, sem sal e sem açúcar, casta esposa de marido respeitador e sóbrio? Que me importa meu conceito na rua e na cidade, meu nome digno? Minha honra de casada, que me importa? Toma de tudo isso em tua boca ardida... queima em teu fogo a minha decência inata, rasga com tuas esporas meu pudor antigo, sou tua cadela, tua égua, tua puta.

(AMADO, 1976b, p. 35) 
Como espírito, Vadinho conhecia a vida e a morte e como malandro conhecia a ordem e a desordem, o mundo das relações pessoais e o mundo das leis e dos regulamentos impessoais. Comparando a vida de casada com Teodoro, os bens materiais que ganhou no segundo casamento, com relação dos dois antes de sua morte, ele falou a Dona Flor:

A casa própria, a fidelidade conjugal, o respeito, a ordem, a consideração e a segurança. Quem te dá é ele, pois o seu amor é feito dessas coisas nobres (e cacetes) e delas todas necessitas para ser feliz. Também do meu amor precisas para ser feliz, desse amor de impurezas, errado ou torto, devasso e ardente, que te faz sofrer. Amor tão grande que resiste à minha vida desastrada, tão grande que depois de não ser voltei a ser e aqui estou.

E completa Vadinho, sabiamente: "Quando era só eu, tinhas meu amor e te faltava tudo, como sofrias! Quando foi só ele, tinhas de um tudo, nada te faltava, sofrias ainda mais. Agora, sim, és Dona Flor inteira como deves ser".

(AMADO, 1976b, p.366) 
$\mathrm{Na}$ condição de morto que voltou ao mundo dos vivos, Vadinho não mudou, em nada difere daquele homem quando vivo. Continua o mesmo malandro de antes. De certa forma, o autor nos mostrou que a possibilidade do seu "retorno" ao mundo dos vivos, pela utilização de elemento fantástico, não modificou seu comportamento. Era de se supor, que na condição de morto atingisse a redenção e a purgação das culpas. Porém, a consciência que está morto e, portanto, isento das censuras dos vivos, tendo sua "volta" percebida apenas por Flor, sentia-se livre para pensar e agir como antes, tanto que se considerava, também, marido de Flor. Assim, decidiu ficar e participar ativamente do cotidiano de Flor, dando-se o direito de ironizar e fazer gozação ao referir-se a Teodoro, reafirmando que os dois (ele e Flor) estão casados.

- Me deixa dormir, cheguei faz pouco.

- Tu não pode dormir na sala

- O que é que tu tem?

- Já te disse, fico sem jeito.

$[\ldots]$

- Tá bom, tola. Vou para o quarto. O meu colega já saiu?

- Colega?

- O teu doutor... Não somos os dois casados contigo, meu bem [...] (p.301). 
Livre da "visão" das outras personagens e das sensações que poderiam ser atribuídas a seus atos, volta à vida boêmia, ao convívio dos amigos malandros e, principalmente a assediar as alunas de Flor. Como fazia antes da morte. Assim, por exemplo, quis se certificar da originalidade dos seios "[...] da abundante Zulmira Simões Fagundes, crioula augusta, [..]. quadris soltos independentes, seios de bronze (ao menos pareciam) [...] (AMADO, 1976b, p. 302).

Vadinho quis tirar a limpo de uma vez por todas o enigma dos seus seios: seriam mesmo de bronze ou apenas de extraordinariamente rigidez. Para tanto, elevou-se no ar e pondo-se com os pés para cima e a cabeça para baixo, expiou pelo decote do vestido da primorosa da nação nagô. (p.302).

O que aconteceu, no caso de Dona Flor, não foi a recusa do ambíguo, mas a busca e a aceitação plenamente consciente de dois homens diferentes e, com eles, formar um triângulo amoroso perfeito. Até o final da narrativa, Flor passou a conviver com os "dois maridos" nesse nível de existência ficcional fantástica. 


\section{Considerações Finais}

No mundo real que é exatamente o nosso, a produção de um acontecimento que não pode ser explicado pelas leis deste mesmo mundo familiar, ou se trata de uma ilusão, ou então o acontecimento realmente ocorreu. O fantástico ocorre nesta incerteza; ao escolher uma ou outra resposta, deixa-se o fantástico para entrar num gênero vizinho, como o estranho, por exemplo.

O que há no final da narrativa de Quincas Berro d'Água é a história de um homem que abandonou a vida de cidadão passou a viver na boemia. Quincas Berro d'Água é uma personagem que desafiou a morte. Ele não é um insubmisso, mas sua revolta foi muito além da rebeldia contra as mazelas sociais e se expande para uma revolta contra os limites da condição humana e as determinações do destino.

A sua morte em alto-mar significa um grito de liberdade, porque, irmanado ao povo, aos vagabundos e desqualificados, e ao deixar de ser o pobre Joaquim Soares da Cunha, explorado pela família, ganhou uma grandeza que não possuía antes, a de escolher o seu próprio destino, ter a morte desejada e escolhida: morrer no mar, com todas as honras de velho marinheiro.

Há ainda diversas interpretações da sociedade sobre a morte nas condições da morte do herói, Quincas. A morte de um homem, por mais testemunhada que seja por autoridades competentes e objetivas sempre deixa portas abertas para o mistério, para as condições próprias do ser humano. Além 
disso, quanto mais duvidosa for a morte, mais o espírito da morte sobrevive social e psicologicamente.

Por outro lado, predomina na narrativa de Dona Flor e seus dois maridos a luta psíquica da personagem Flor, na tentativa de superar os preconceitos impostos pela sociedade. Sem se render a esses preconceitos, se entregou aos desejos e instintos e, enfim, se dá o direito de amar dois homens. Jorge Amado põe em cena uma heroína que não precisou mais escolher entre o bem e o mal, isto porque, dividida entre o falecido e sensual Vadinho e a nova paixão pelo metódico Teodoro, ela ficou com os dois.

Contrariando o que afirma Todorov que, no fim de uma história, o leitor, quando não a personagem toma, contudo, uma decisão, opta por um, ou outra solução, saindo desse modo do fantástico, o final das duas narrativas estudadas, o fantástico permanece e possibilita a realização dos desejos intensos das personagens: a segunda morte de Quincas Berro d'Água no mar como velho marinheiro e em Dona Flor e seus dois maridos é a volta e aceitação de Vadinho e decisão de Flor de ficar com os dois maridos.

\section{Referências}

AMADO, Jorge. A morte e a morte de Quincas Berro d'Água. In Os velhos marinheiros. Rio de Janeiro: Livraria Martins Editora, 1976a. 
. Dona Flor e seus dois maridos. Rio de Janeiro:

Livraria Martins Editora, 1976b.

RODRIGUES, Selma C. O fantástico. São Paulo: Ática, 1988.

TODOROV, T. As estruturas narrativas. São Paulo: Ed. Perspectiva, 1979.

TODOROV, Tzvetan. Introdução à literatura fantástica. Trad. De Maria Clara Corra Castello. São Paulo: Perspectiva, 1975.

VAX, Louis. A arte e a literatura fantástica. Lisboa: Arcádia, 1974. 